\title{
Paravaginal female adnexal tumor of probable Wolffian origin mimicking vaginal spindle cell epithelioma on biopsy
}

\author{
Ryan Yu*1, Brigitte Courteau ${ }^{1}$, Ryan Rebello ${ }^{2,3}$, Alice Lytwyn ${ }^{1,4}$, Monalisa Sur ${ }^{1,4}$, Salem Alowami ${ }^{1,3}$ \\ ${ }^{1}$ Department of Pathology and Molecular Medicine, McMaster University, Hamilton, Ontario Canada \\ ${ }^{2}$ Department of Radiology, McMaster University, Hamilton, Ontario Canada \\ ${ }^{3}$ St. Joseph's Hospital, Hamilton, Ontario, Canada \\ ${ }^{4}$ Juravinski Hospital and Cancer Centre, Hamilton Health Sciences, Hamilton, Ontario, Canada
}

Received: September 16, 2019

DOI: $10.5430 /$ crcp.v6n1p32
Accepted: October 18, 2019

Online Published: November 23, 2019

\begin{abstract}
Female adnexal tumor of probable wolffian origin (FATWO) is a tumor of low malignant potential that arises predominantly in the broad ligament, mesosalpinx, and ovarian hilus. The rarity of FATWO increases its susceptibility to misdiagnosis as other tumors, especially when it occurs at an unusual site. We report a 29 -year old woman with a $7.2 \mathrm{~cm}$ left paravaginal FATWO that invaded into the vaginal lumen. The initial biopsy demonstrated features suggestive of vaginal spindle cell epithelioma, but with increased Ki67 proliferation index. Pathologists should be aware that the common sieve-like architecture of FATWO may not be apparent on small biopsies, which by sampling error may demonstrate predominantly the less common spindle cell architecture. Awareness of FATWO in the differential diagnosis of paravaginal tumors may help to avoid misinterpretation as vaginal spindle cell epithelioma, a previously unappreciated pitfall in the diagnosis of FATWO.
\end{abstract}

Key Words: Female adnexal tumor of probable Wolffian origin, Spindle cell epithelioma

\section{INTRODUCTION}

Female adnexal tumor of probable wolffian origin (FATWO) was first described in 1973 by Kariminejad and Scully, ${ }^{[1]}$ who documented nine cases of a tumor composed of epithelial cells growing in a diffuse, trabecular, and tubular pattern arising in the broad ligament or mesosalpinx. Since then, rare cases have occurred in other locations, including the retroperitoneum ${ }^{[2]}$ and paravagina. ${ }^{[3]}$ We report a 29 -year old woman with a paravaginal FATWO that mimicked vaginal spindle cell epithelioma on biopsy.

\section{CASE REPORT}

A 29-year old woman, gravida 2 para 2, presented to her family physician with a 3-week history of irregular vaginal bleeding. A mass eroding into the vaginal lumen was found. Magnetic resonance imaging (MRI) demonstrated a $7.2 \mathrm{~cm}$ mass at the lower left pelvis. It was separate from the cervix and remainder of the uterus. T2-weighted images showed mild heterogeneity but overall moderate hyperintensity (see Figure 1 (a)). It was hemorrhagic on T1-weighted images, demonstrating bright signal on fat-saturated and non-fat-saturated images. Post-gadolinium sequences dis-

\footnotetext{
*Correspondence: Ryan Yu; Email: ryan.yu@medportal.ca; Address: McMaster University, Department of Pathology and Molecular Medicine, HSC-2N10, 1280 Main Street West, Hamilton, ON, Canada.
} 
played avid homogeneous enhancement (see Figure 1 (b)). No necrotic areas were seen. Biopsy showed mixed spindle and epithelial cell elements. There was predominance of spindle cells arranged mostly in solid sheets (see Figure 2 (a)). The epithelial component showed few areas of glandular differentiation. There was mild cellular atypia and numerous apoptotic cells. Mucicarmine stain was focally positive. On immunohistochemistry, the tumor cells were diffusely positive for cytokeratin (CK) 7, AE1/AE3, low molecular weight $\mathrm{CK}$, high molecular weight $\mathrm{CK}$, CD56, p16, CD10, CD31 and vimentin. They were focally positive for desmin, calretinin and actin and negative for ER and PR. The Ki67 proliferation index was 15\%-20\%. The findings were suggestive of vaginal spindle cell epithelioma. Given the fragmented nature of the biopsy and Ki67 proliferation index, complete excision was recommended for further assessment. The tumor was confirmed intraoperatively as paravaginal and resected without complication. No adjuvant therapy was prescribed. No recurrence or metastasis was found at 8 months follow-up.
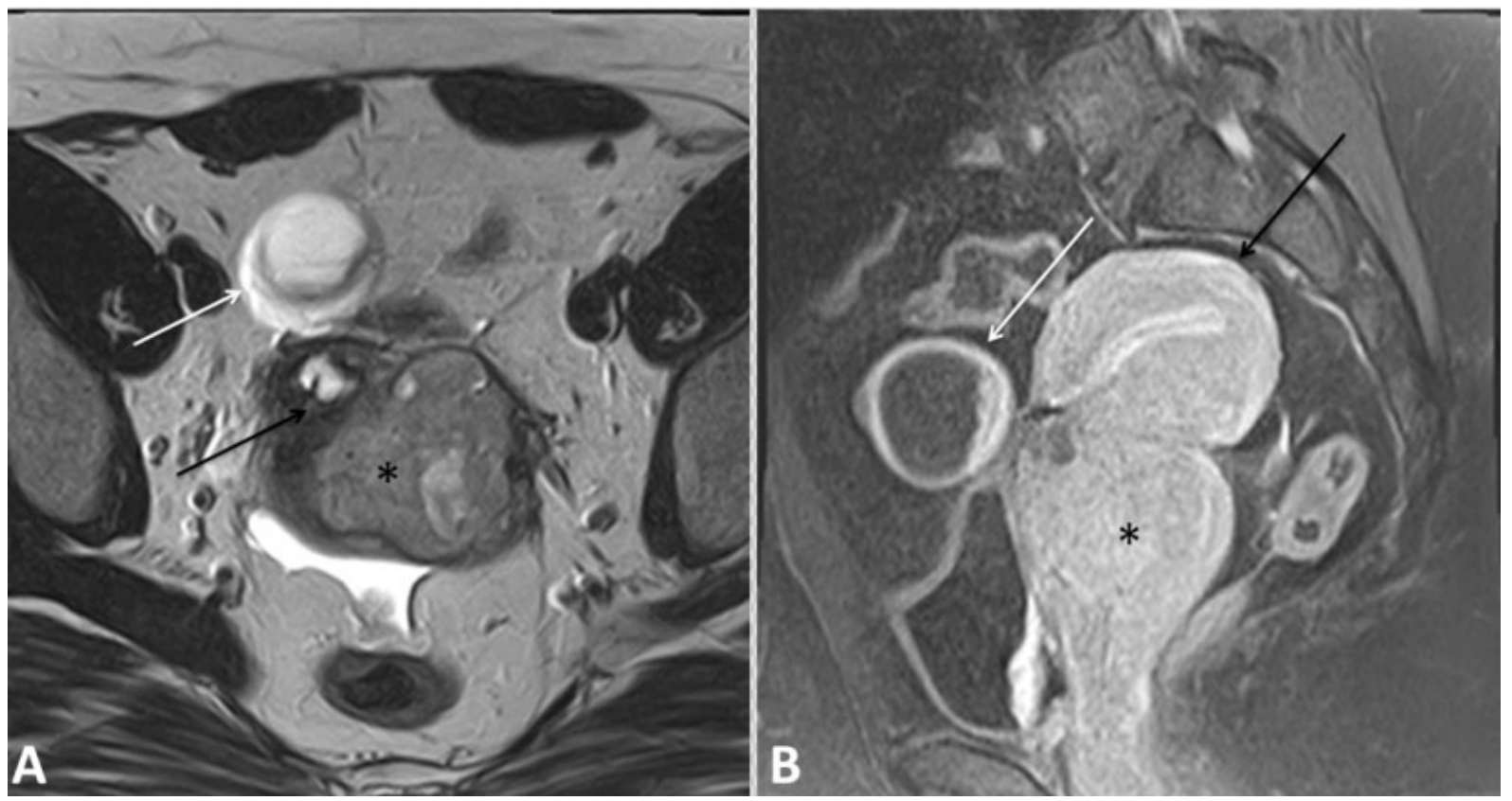

Figure 1. (A) Axial T2-weighted image demonstrates a tumour (*), to the left of the cervix (black arrow). The mass is seen within the vaginal/paravaginal tissue and is slightly heterogeneous with moderate $\mathrm{T} 2$ hyperintensity. A benign right ovarian cyst is noted (white arrow) and there is a small volume of physiologic free fluid in the cul-de-sac. (B) Sagittal post-contrast fat-saturated T1-weighted image demonstrates the large mass (*) within the vagina, below the uterus (black arrow). It demonstrates homogeneous avid enhancement, similar to myometrium. The incidental right ovarian cyst (white arrow) is again noted.

On microscopic examination, a well-circumscribed tumor composed of epithelioid spindle cells was found deep in the vaginal wall (see Figure 2 (b)). Although solid areas were present, the tumor cells were arranged predominantly in a sieve-like pattern that was less conspicuous in the biopsy (see Figure 3 (a)). There were tubules and cysts of variable size and shape, many of which contained eosinophilic, colloid-like material (see Figure 3 (b)). Part of the tumor showed hyalinized fibrous papillary architecture lined by cuboidal to flat epithelial cells (see Figure 3 (c)). Thin-walled blood vessels were present, without a hemangiopericytomalike pattern. Cytologic atypia was minimal. Mitoses were identified at 4 per 10 high-power fields. The tumor cells showed positive immunostaining for AE1/AE1, CAM 5.2, CK7, 34bE12, MOC31, p16, CD99, CD56, and CD57. EMA, $\mathrm{CD} 10$, and calretinin were focally positive. The tumor cells were negative for vimentin, myogenin, desmin, AFP, Bcl-2, inhibin, WT-1, CEA, and CD117/c-kit. CD31, CD34 and SMA were positive within blood vessels only. The findings were consistent with FATWO. Fluorescence in situ hybridization analysis using a probe for the SS18 (18q11.2) gene, to exclude synovial sarcoma, showed no evidence of the SS18 rearrangement. 


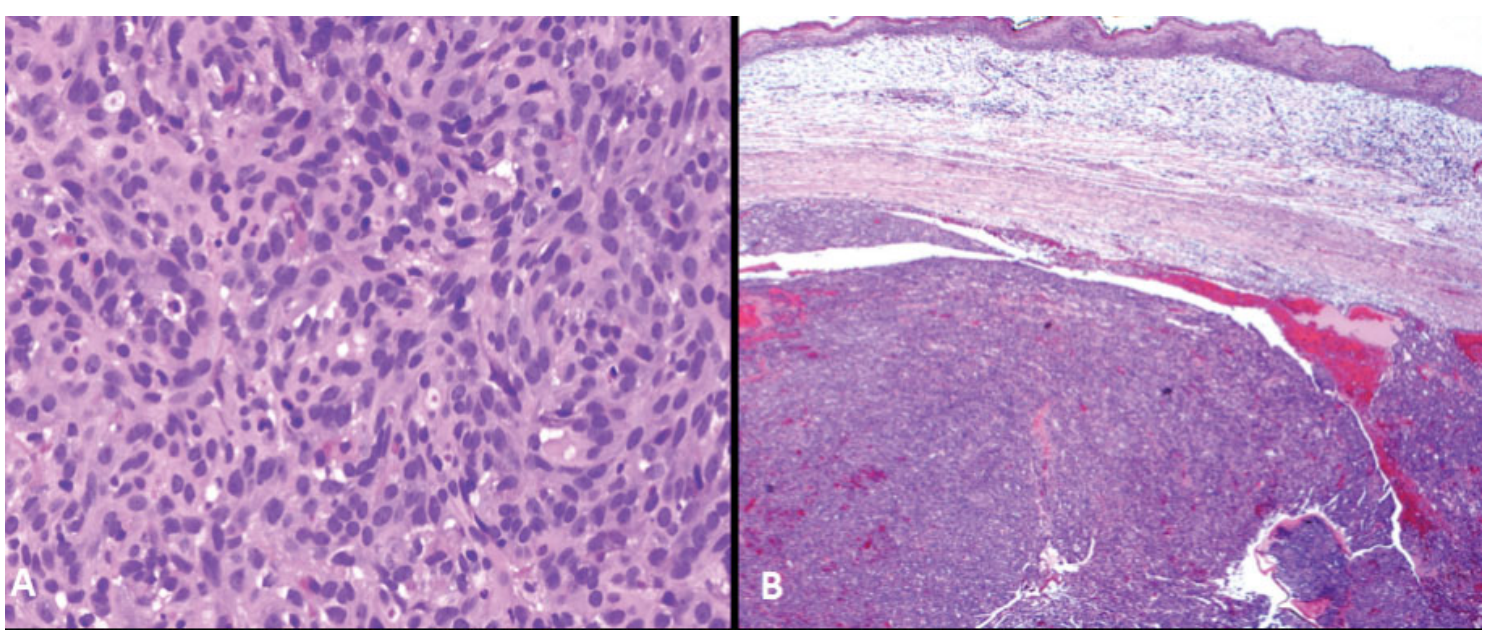

Figure 2. (A) Biopsy showing uniform epithelioid spindle cells (H\&E, 200x). (B) Excision specimen with a well-circumscribed tumor in the vaginal wall (H\&E, 40x).

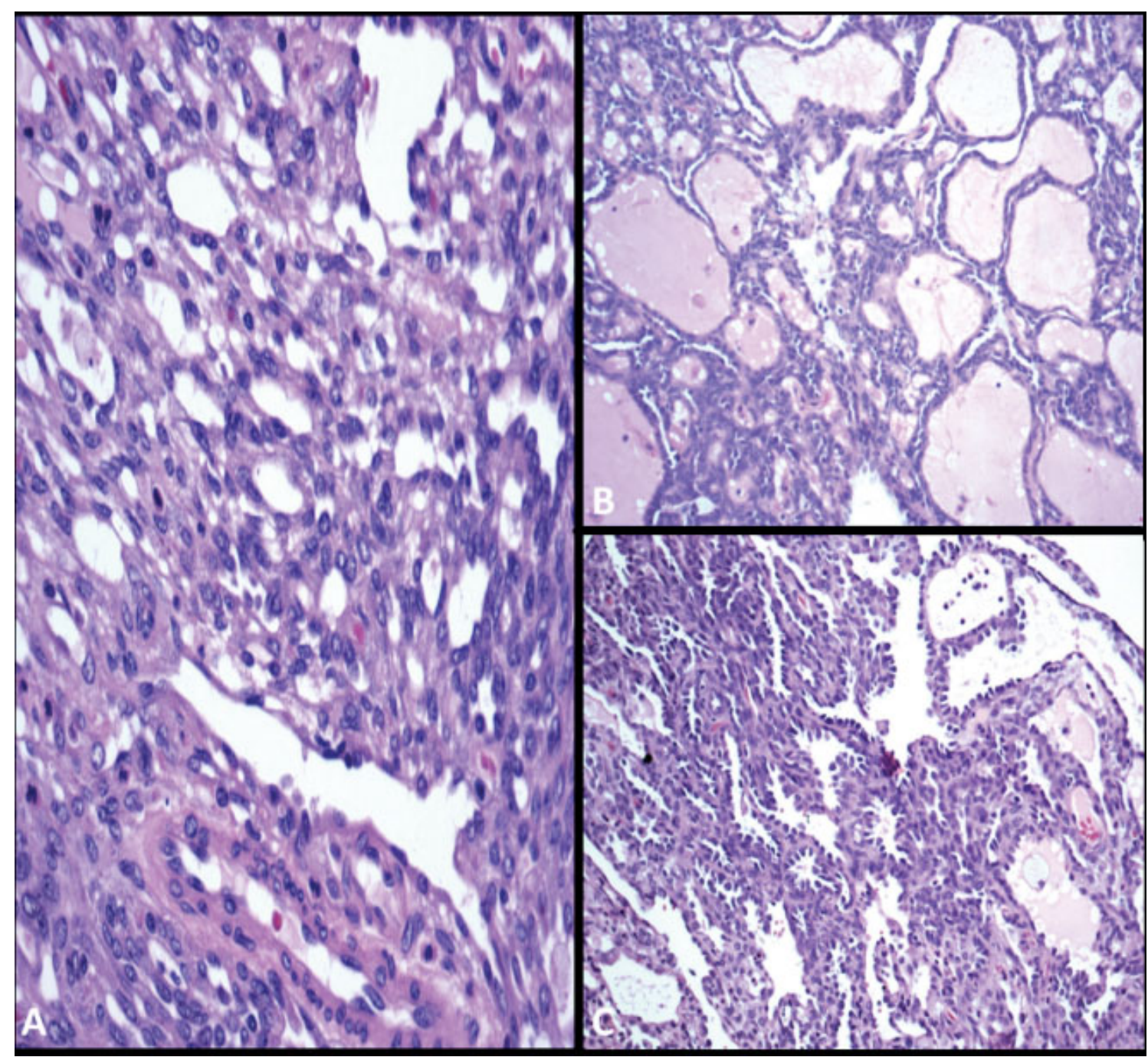

Figure 3. (A) Sieve-like architecture (H\&E, 200x). (B) Tubulocystic architecture (H\&E, 100x). (C) Hyalinized fibrous papillary architecture (H\&E, 100x). 


\section{Discussion}

FATWO is rare. It is thought to be of mesonephric (Wolffian) origin because it arises at sites where mesonephric duct remnants are found, that is from the hilum of the ovary, along the mesosalpinx and down the lateral edges of the uterus to the outer third of the vagina. Paravaginal FATWO is very rare relative to those that arise in the broad ligament and mesosalpinx. Although most patients with FATWO are middle-aged, paravaginal FATWOs reported to date, including the current case, have occurred in younger adults. ${ }^{[3-5]}$ The clinical presentation of paravaginal FATWO is similar to that of FATWO at other sites. Patients may be asymptomatic with the tumor found incidentally through routine pelvic examination or imaging for a non-gynecologic indication. When symptomatic, non-specific abdominal or pelvic pain is common. Paravaginal FATWO is a rare cause of vaginal bleeding. On MRI, FATWO is reportedly isointense with skeletal muscle on T1-weighted images and hyperintense on T2-weighted images. ${ }^{[6-8]}$

FATWO exhibits a variety of architectural patterns. Tumor cells may be arranged in diffuse solid sheets or closelypacked tubules which impart a dense solid appearance on low-power magnification. The tubules show winding, branching and anastomosis and are lined by cuboidal or columnar cells. A tubulocystic, sieve-like pattern is most commonly observed. There are hollow tubules of variable size and shape, occasionally with pointed ends or cyst formation. Some tubules contain dense, colloid-like, PAS-positive material. Between the tubules, there are often fusiform spindle cells. The various architectural patterns of FATWO frequently coexist, but a single pattern may predominate. The tumor cells have scant cytoplasm and round to oval, hyperchromatic nuclei with inconspicuous nucleoli. Mitotic figures are rare to absent. Degenerative changes, including necrosis and hemorrhage, may be found but are not prominent. Immunohistochemistry, which has been used to investigate the origin of FATWO, is of limited diagnostic utility. FATWO tends to show diffusely positive staining for AE1/AE3, CAM5.2, $34 \beta \mathrm{E} 12$, and calretinin; focal staining for CK7 and CD10; and no staining for CK20 and EMA. ${ }^{[9,10]}$

In this case, the main differential diagnosis includes vaginal spindle cell epithelioma, endometrial carcinoma, and monophasic synovial sarcoma. Vaginal spindle cell epithelioma is characterized by an admixture of epithelial and mesenchymal components, absence of sieve-like architecture, and low Ki67 (less than 10\%). Endometrial carcinoma demonstrates greater cytological atypia, mitotic activity, foci of squamous differentiation, and is calretinin negative. Monophasic synovial sarcoma shows focal herringbone architecture, frequent hemangiopericytomatous vessels,

Published by Sciedu Press
EMA immunoreactivity, and the SYT-SSX gene fusion. Additionally, sex cord-stromal tumors may mimic FATWO, especially Sertoli cell tumor. However, sex cord-stromal tumors tend to arise in the ovary and in this context, immunohistochemistry with SF1 may be a useful test to distinguish from FATWO. ${ }^{[1]}$

Molecular genetic characterization of FATWO is limited. Kwon et al. ${ }^{[12]}$ found promoter methylation of the tumor suppressor gene O-6-methylguanine-DNA methyltransferase (MGMT). Mirkovic et al. ${ }^{[13]}$ found frequent mutations of unknown significance in the histone methyltransferase KMT2D gene. Cossu et al. ${ }^{[14]}$ found missense mutations in CTNNB1, MET, PIK3CA, BRAF and TP53. Mutations have not been found in KRAS, NRAS, PTEN, DICER1, KIT or PDGFR genes. ${ }^{[13,15,16]}$

Most FATWOs exhibit benign behavior. According to Li et al., ${ }^{[10]}$ preservation of the E-cadherin-catenin complex and low Ki-67 labeling index may explain the indolent behavior and low malignant potential of FATWO. However, aggressive cases with local recurrence and metastasis have been reported ${ }^{[17-19]}$ Distinguishing benign from malignant FATWO is a challenging clinicopathologic problem. Findings proposed as suggestive of aggressive behavior include hypercellularity, cellular pleomorphism, high mitotic activity, and necrosis. ${ }^{[20]}$ However, the stage of presentation may correlate better with outcome than morphologic features. ${ }^{[21]}$ Given the small number of recurrent and metastatic cases, there is little evidence for management recommendations. Surgical debulking with total abdominal hysterectomy-bilateral salpingo-oophorectomy appears to be the most successful initial treatment. The role of chemotherapy and radiotherapy is unknown and not standardized. CHOP therapy, performed in one case of FATWO with concurrent lymphoma, did not have noticeable effect on FATWO. ${ }^{[22]}$ Imatinib, a tyrosine kinase inhibitor, was used by Steed et al. ${ }^{[23]}$ for recurrent FATWO that was immunohistochemically CD117/c-kit positive with favorable response. But mutational analysis was not reported in that case, and FATWOs that are CD117/c-kit positive by immunohistochemistry do not necessarily harbor known ckit mutations. ${ }^{[15,24]}$ Combination carboplatin/paclitaxel was used in addition to imatinib and surgical debulking with near complete response in one case of recurrent FATWO. ${ }^{[16]}$ Given that some FATWOs express estrogen and progesterone receptors, hormonal therapy may be an option in cases where other treatments have failed. ${ }^{[25]}$

In conclusion, pathologists and gynecologic oncologists should be aware that FATWO may arise at sites other than the broad ligament and mesosalpinx, such as the paravagina. FATWO exhibits a variety of histologic architectural pat- 
terns, most commonly sieve-like, which guides the pathologist in rendering a morphologic diagnosis of FATWO. However, the sieve-like architecture may not be apparent or wellappreciated on small biopsies. Sampling error in a biopsy may demonstrate predominantly the less common spindle cell architecture of FATWO, which is susceptible to misdiagnosis as spindle cell epithelioma if FATWO arises in the unusual paravaginal location. Awareness of FATWO in the differential diagnosis of paravaginal tumors may help to avoid misinterpretation as vaginal spindle cell epithelioma, which is a previously unrecognized pitfall in the diagnosis of FATWO. The distinction is clinically important as vaginal spindle cell epithelioma is benign, while FATWO is best regarded as potentially malignant. A definitive diagnosis of vaginal spindle cell epithelioma should be made only reluctantly in a biopsy with high Ki67. The immunoprofile should not be used as the main criteria to diagnose FATWO, the gold standard of which is clinicopathologic correlation.

\section{CONFLICTS OF INTEREST DisClOSURE}

The authors declare that they have no competing interests.

\section{REFERENCES}

[1] Kariminejad MH, Scully RE. Female adnexal tumor of probable Wolffian origin. A distinctive pathologic entity. Cancer. 1973; 31: 671-677. https://doi.org/10.1002/1097-0142(197303)31: 3<671: : AID-CNCR2820310328>3.0.CO;2-K

[2] Sivathondan Y, Salm R, Hughesdon PE, et al. Female adnexal tumour of probable Wolffian origin. J Clin Pathol. 1979; 32: 616-624. PMid:469017. http://dx.doi.org/10.1136/jcp.32.6.616

[3] Hinchey WW, Silva EG, Guarda LA, et al. Paravaginal wolffian duct (mesonephros) adenocarcinoma: a light and electron microscopic study. Am J Clin Pathol. 1983; 80: 539-544. PMid:6624720. https://doi.org/10.1093/ajcp/80.4.539

[4] Daya D, Murphy J, Simon G. Paravaginal female adnexal tumor of probable wolffian origin. Am J Clin Pathol. 1994; 101: 275-278. https://doi.org/10.1093/ajcp/101.3.275

[5] Basheska NT, Yashar G, Kubelka K, et al. Paravaginal female adnexal tumor of probable Wolffian origin: A case report. Virchows Arch 1999; 435: 230.

[6] Matsuki M, Kaji Y, Matsuo M. Female adnexal tumour of probable Wolffian origin: MR findings. Br J Radiol. 1999; 72 911-913. PMid:10645202. http://dx.doi.org/10.1259/bjr.7 2.861 .10645202

[7] Sato T, Isonishi S, Sasaki K et al. A case of female adnexal tumor of probable Wolffian origin: Significance of MRI findings. Int Canc Conf J. 2012; 1: 108-112. http://dx.doi .org/10.1007/s1369 1-012-0021-6

[8] Sakai M, Abiko K, Matsumura N, et al. Two cases of Wolffian tumor with novel magnetic resonance imaging findings reflecting characteristic pathology. J Obstet Gynaecol Res. 2016; 42: 1046-1051. PMid:27125724. http://dx.doi.org/10.1111/jog. 13020

[9] Devouassoux-Shisheboran M, Silver SA, Tavassoli FA. Wolffian adnexal tumor, so-called female adnexal tumor of probable Wolffian origin (FATWO): immunohistochemical evidence in support of a Wolffian origin. Hum Pathol. 1999; 30: 856-863. https: //doi.org/10.1016/S0046-8177 (99) 90148-X

[10] Li CC, Qian ZR, Hirokawa M, et al. Expression of adhesion molecules and $\mathrm{Ki}-67$ in female adnexal tumor of probable Wolffian origin (FATWO): report of two cases and review of the literature. APMIS. 2004; 112: 390-398. PMid:26352548. https://doi.org/ 10.1111/j.1600-0463.2004.t01-1-apm1120602.x

[11] Goyal A, Masand RP, Roma AA. Value of PAX-8 and SF-1 Immunohistochemistry in the Distinction Between Female Adnexal Tumor of Probable Wolffian Origin and its Mimics. Int J Gynecol Pathol.
2016; 35: 167-175. https://doi.org/10.1097/PGP. 00000000 00000222

[12] Kwon MJ, Yun MJ, Kim MK. A female adnexal tumor of probable Wolffian origin showing positive O-6-methylguanine-DNA methyltransferase methylation. Obstet Gynecol Sci. 2016; 59: 328-332. PMid:27462603. https://doi.org/10.5468/ogs .2016.59.4. 328

[13] Mirkovic J, Dong F, Sholl LM, et al. Targeted Genomic Profiling of Female Adnexal Tumors of Probable Wolffian Origin (FATWO). Int J Gynecol Pathol. 2019; 38: 543-551. PMid:30134342. https : //doi.org/10.1097/PGP.0000000000000545

[14] Cossu A, Casula M, Paliogiannis P, et al. Female Adnexal Tumors of Probable Wolffian Origin (FATWO): A Case Series With NextGeneration Sequencing Mutation Analysis. Int J Gynecol Pathol. 2017; 36: 575-581. PMid:28463911. https://doi.org/10.109 7/PGP. 0000000000000368

[15] Harada O, Ota H, Takagi K, et al. Female adnexal tumor of probable wolffian origin: morphological, immunohistochemical, and ultrastructural study with c-kit gene analysis. Pathol Int. 2006; 56: 95-100. PMid:16445822. https://doi.org/10.1111/j.1440-1827.20 $06.01930 . x$

[16] Wakayama A, Matsumoto H, Aoyama H, et al. Recurrent female adnexal tumor of probable Wolffian origin treated with debulking surgery, imatinib and paclitaxel/carboplatin combination chemotherapy: A case report. Oncol Lett. 2017; 13: 3403-3408. PMid:28529572. https://doi.org/10.3892/o1.2017.5874

[17] Sheyn I, Mira JL, Bejarano PA, et al. Metastatic female adnexal tumor of probable Wolffian origin: a case report and review of the literature. Arch Pathol Lab Med. 2000; 124: 431-434.

[18] Deshimaru R, Fukunaga T, Sato T, et al. A case of metastatic female adnexal tumor of probable Wolffian origin. Gynecol Oncol Rep. 2014; 10: 22-24. PMid:26075996. https://doi.org/10.1016/ j.gore. 2014.07.001

[19] Deen S, Duncan TJ, Hammond RH. Malignant female adnexal tumors of probable Wolffian origin. Int J Gynecol Pathol. 2007; 26: 383-386. PMid:17885487. https://doi.org/10.1097/pgp. Ob $013 e 3180645136$

[20] Lee JE, Kwon YS, Koo YJ, et al. High malignant female adnexal tumor of probable wolffian origin (FATWO): A case report. Korean J Obstet Gynecol. 2010; 53: 75-79. https ://doi . org/10.5468/ kjog.2010.53.1.75

[21] Heatley MK. Is female adnexal tumour of probable wolffian origin a benign lesion? A systematic review of the English literature. Pathol- 
ogy. 2009; 41: 645-658. PMid:20001344. https://doi.org/10 $.3109 / 00313020903273084$

[22] Karaca M, Sevinc A, Aydin A, et al. Female adnexal tumor of probable Wolffian origin diagnosed during the staging evaluation of extranodal diffuse large B-cell lymphoma. Leuk Lymphoma. 2005; 46: 929-933. PMid:16019541. https://doi.org/10.1080/104281 90500054327

[23] Steed H, Oza A, Chapman WB, et al. Female adnexal tumor of probable wolffian origin: a clinicopathological case report and a possible new treatment. Int J Gynecol Cancer. 2004; 14: 546-550. PMid:15228432.

[24] Syriac S, Durie N, Kesterson J, et al. Female adnexal tumor of probable Wolffian origin (FATWO) with recurrence 3 years postsurgery. Int J Gynecol Pathol. 2011; 30: 231-235. PMid:21464731. https://doi.org/10.1097/PGP.0b013e3182005340

[25] Atallah D, Rouzier R, Voutsadakis I, et al. Malignant female adnexal tumor of probable wolffian origin relapsing after pregnancy. Gynecol Oncol. 2004; 95: 402-404. PMid:15491766. https ://doi .org/10 $.1016 /$ j . ygyno. 2004.07.042 